\title{
Estudo das condições de obtenção do filme viniltrietoxisilano na proteção contra a corrosão do aço galvanizado
}

\author{
Study of the Obtaining Conditions of \\ Vinyltretoxysilane Film as Corrosion \\ Protection of the Galvanized Steel
}

Tarcilla Silva dos Santos ${ }^{1}$, Fernando Cotting ${ }^{2}$, Vera Rosa Capelossi ${ }^{1}$

\author{
${ }^{1}$ Laboratório de Materiais e Meio Ambiente -LAMMA - Universidade Estadual de Santa Cruz, Rod. Jorge Amado, Km \\ 16, Ilhéus, BA, Brasil. \\ ${ }^{2}$ Laboratório de Corrosão e Engenharia de Superfícies - Departamento de Engenharia Química - Universidade Federal \\ de Minas Gerais, Minas Gerais, Belo Horizonte, Brasil. \\ e-mail: tarcillasantos@yahoo.com.br, vera.rosa@gmail.com, fernandocotting@gmail.com
}

\section{RESUMO}

O aço galvanizado é obtido pela imersão do aço carbono em um banho de zinco fundido, sendo esse material muito utilizado na indústria automotiva e de eletrodomésticos. Como todo material metálico, é suscetível à corrosão quando exposto a ambientes corrosivos, necessitando assim de tratamento de superfície para proteção. Atualmente, são utilizados como pré-tratamentos a fosfatização e a cromatização, ambos com restrições ambientais e à saúde humana. $\mathrm{O}$ aço galvanizado é obtido pela imersão do aço carbono em um banho de zinco fundido, sendo esse material muito utilizado na indústria automotiva, petroquímica, química, naval, aeronáutica e de linha branca. Apresenta maior resistência à corrosão do que o aço carbono quando exposto a ambientes corrosivos. Para aumentar sua durabilidade e sua resistência à corrosão, passa por um tratamento superficial que seja aderente à sua superfície. Por esta razão, atualmente, são utilizados a fosfatização e a cromatização como pós-tratamento à galvanização, ambos com restrições ambientais e à saúde humana. Por essa razão, estuda-se a viabilidade do uso de silanos como possíveis substitutos a essas substâncias por serem menos tóxicos. O silano é um composto organofuncional que atua como agente de acoplamento entre superfícies orgânicas e inorgânicas, bem como pode fornecer proteção contra a corrosão. O objetivo deste trabalho é avaliar a resistência à corrosão do aço galvanizado tratado com filme de silano viniltrietoxisilano (VS) nas condições de hidrólise: concentração de silano (2\%, $3 \%$ e $4 \%$ de silano) e tempo de hidrólise da solução (30 min, 45 min e $60 \mathrm{~min}$ ), mantendo fixos o pH 4,0 da solução solvente água/etanol (50\% v/v), a temperatura de cura $\left(150^{\circ} \mathrm{C}\right)$ e o tempo de cura $(120 \mathrm{~min})$. A resistência à corrosão do aço galvanizado tratado com filme de silano VS foi avaliada através de técnicas eletroquímicas como potencial de circuito aberto, espectroscopia de impedância eletroquímica (EIE), resistência à polarização linear (Rp) e curvas de polarização potenciodinâmicas em solução de $\mathrm{NaCl}$ 0,1 mol.L-1.A resistência à corrosão do aço galvanizado tratado com filme de silano VS foi avaliada através das seguintes técnicas eletroquímicas: potencial de circuito aberto (OCP), espectroscopia de impedância eletroquímica (EIE), resistência à polarização linear (Rp) e curvas de polarização potenciodinâmicas em solução de $\mathrm{NaCl}$ 0,1 mol.L-1. A caracterização química dos filmes foi feita através da técnica de espectroscopia na região do infravermelho (IR). A caracterização morfológica do aço galvanizado tratado foi analisada por microscopia eletrônica de varredura (MEV) e espectroscopia de dispersão de energia de raios X (EDS). Os resultados obtidos para as condições estudadas mostraram a formação de um filme eficiente na proteção contra a corrosão quando o aço galvanizado é pré-tratado com filme obtido na concentração de $4 \%$ de silano e 60 min de tempo de hidrólise. Os resultados eletroquímicos indicaram a formação de um filme eficiente na proteção contra a corrosão quando o aço galvanizado é tratado com filme obtido na concentração de $4 \%$ de silano e 60 min de tempo de hidrólise. As imagens de MEV revelaram uma menor formação de produto de corrosão quando o aço galvanizado é tratado com o filme de silano e os espectros de EDS apresentaram picos de Si indicando a aderência do filme no superfície do aço galvanizado. Já os espec- 
tros na região do IR apresentaram bandas de compostos contendo Si o que revelam a presença do filme de silano na superfície do substrato.

Palavras-chave: aço galvanizado, corrosão, silano, EIE.

\section{ABSTRACT}

Galvanized steel is obtained by immersing the carbon steel in a molten zinc bath widely employed in the automotive, petrochemical, chemical, marine, aeronautical and white-good appliances. It has higher corrosion resistance than carbon steel when exposed to corrosive environments. To increase its durability and corrosion resistance, it undergoes a surface treatment that is adherent to its surface. For this reason, phosphatization and chromatization are currently used as an after treatment to galvanization, both with environmental restrictions and human health. Due to the presence of toxic and carcinogenic products - in the chromatization or phosphatization - and to minimize the impact on the environment, the development of silane films as alternative pretreatments have been studied due to their good physical barrier properties against diffusion of oxygen to the metal interface and improve corrosion resistance. The aim of this work is to evaluate a corrosion resistance performance of galvanized steel coated with vinyltriethoxysilane (VS) film under hydrolysis conditions: silane concentration $(2 \%, 3 \%$ and $4 \% \% \mathrm{v})$ and hydrolysis time (30 min, $45 \mathrm{~min}$ and $60 \mathrm{~min})$. The fixed variables were: the solvent solution used was water/ethanol $(50 \% \mathrm{v} / \mathrm{v})$ at $\mathrm{pH} 4.0$, the curing time of $120 \mathrm{~min}$ and the curing temperature of $150^{\circ} \mathrm{C}$ in an oven. The corrosion resistance of pre-treated galvanized steel with VS silane film was evaluated by the following electrochemical techniques: open circuit potential (OCP), electrochemical impedance spectroscopy (EIS), linear polarization resistance (Rp) and potentiodynamic polarization curves in 0.1 mol.L-1 $\mathrm{NaCl}$ solution. The chemical properties of films were analyzed by infrared spectroscopy technique (IR). The galvanized steel and the film surface morphology were observed by scanning electron microscopy (SEM) and X-ray energy dispersion spectroscopy (EDX). The electrochemical results indicated the formation of an efficient corrosion protection film when galvanized steel is treated with film obtained at $4 \%$ silane concentration and 60 min hydrolysis time. SEM images revealed less corrosion product formation when galvanized steel is treated with silane film and EDS spectra showed Si peaks indicating the adhesion of the film to the galvanized steel surface. The spectra in the IR region showed bands of Sicontaining compounds that reveal the presence of silane film on the substrate surface.

Keywords: galvanized steel, corrosion, silanes, EIS.

\section{INTRODUÇÃO}

Metais, cerâmicas e polímeros apresentam problemas de corrosão e degradação em maior ou menor escala devido à ação do meio ambiente. A maioria dos materiais metálicos quando expostos a atmosfera tendem a reagir espontaneamente com líquidos ou gases presentes no meio, provocando a corrosão do material [1]. A corrosão metálica, em meio aquoso, caracteriza-se pelo ataque eletroquímico começando pela superfície do material, alterando suas propriedades mecânicas, físicas e até mesmo estéticas [2].

A aplicação de revestimentos metálicos em algumas ligas de ferro mostra-se eficiente em muitas aplicações, melhorando as propriedades de resistência à corrosão, principalmente relacionadas com a fadiga [3]. Os aços ao passarem pelo processo de galvanização são recobertos por uma fina camada de zinco fundido, o qual reagindo com o oxigênio do ar constitui uma camada de óxido que proporciona uma proteção ativa contra a corrosão atmosférica [4]. Assim, o aço galvanizado tem sido utilizado na indústria automotiva, na construção civil, em eletrodomésticos (linha branca), e outras aplicações industriais [5]. No entanto, por conta da baixa espessura, essa camada de óxido de zinco não é capaz de proteger o aço carbono por longos períodos, principalmente em atmosferas muito agressivas.

Para aumentar a vida útil do material e diminuir a ação da corrosão, utilizam-se convencionalmente processos de tratamento de cromatização e fosfatização dos aços galvanizados [1], que apesar de aumentarem a aderência entre o substrato e a camada de pintura, esses tratamentos apresentam algumas desvantagens: na cromatização há uma elevada toxicidade de sais de cromo hexavalente [6] e na fosfatização uma alta geração de resíduos e possibilidade de gerar doenças graves à saúde humana [7]. Visando reduzir riscos à saúde humana e minimizar impactos ambientais, estudos sobre novas tecnologias têm sido desenvolvidos, com o objetivo de diminuir a ação da corrosão no substrato e tornar-se uma alternativa ambientalmente amigável [8]. Neste contexto, surgem os silanos como promissores substitutos a esses tratamentos convencionais.

Os silanos são revestimentos alternativos que oferecem boas propriedades de barreira física contra a difusão de oxigênio na interface do metal e melhoram a resistência à corrosão de diversos metais e ligas [911]. Com a formação de um filme denso e aderente ao substrato, o silano impede a passagem de íons do meio 
para o substrato metálico agindo como uma barreira hidrofóbica [12].

Os filmes de silanos têm sido pesquisados como agentes de acoplamento entre fases orgânicas e inorgânicas, promovendo a adesão entre substratos metálicos e revestimentos orgânicos, além de proteger contra fenômenos de corrosão $[13,14,15]$. Contudo, descobriu-se que a proteção contra a corrosão depende tanto do tipo como das condições da superfície do metal, quanto do sistema de silano depositado sobre o substrato [16].

A utilização de silanos em processos industriais tem sido objeto de pesquisas para buscar as melhores condições de hidrólise, pois estas interferem na formação do filme como: $\mathrm{pH}$ da solução de hidrólise, concentração de silano em solução e seu tempo de hidrólise, tempo e temperatura de cura do filme $[17,18,19,20$, 21]. Cada silano apresenta uma condição de processamento única, o que leva a uma grande quantidade de trabalhos publicados nesse tema.

Neste estudo foi utilizado o viniltrietoxisilano (VS), um monossilano com grupamento funcional vinil, cuja fórmula molecular é $\mathrm{H}_{2} \mathrm{C}=\mathrm{CHSi}\left(\mathrm{OC}_{2} \mathrm{H}_{5}\right)_{3}$. O VS é um agente comum de acoplamento de silano e tem como características ser bom reticulador e ter a presença de uma rede inorgânica e orgânica [22,23,24].

Diante desse contexto, o presente trabalho tem como objetivo avaliar as condições de preparação do filme de silano viniltrietoxisilano (VS), aplicado sobre o aço galvanizado, visando melhorar suas propriedades anticorrosivas. Para tanto, variou-se o tempo de hidrólise e a concentração de silano. A resistência à corrosão foi avaliada por técnicas eletroquímicas e a morfologia da superfície foi analisada por MEV. A caracterização química do filme na superfície do aço galvanizado foi obtida por EDS e IR.

\section{MATERIAIS E MÉTODOS}

As placas de aço galvanizado, com revestimento de zinco de 65,5 g.m-2 recebido da USIMINAS, foram cortadas em uma guilhotina no tamanho $30 \mathrm{~mm} \times 25 \mathrm{~mm} \times 0,9 \mathrm{~mm}$ para os ensaios eletroquímicos e análises de MEV. Após esse procedimento inicial, os corpos-de-prova (cdps) foram limpos manualmente com algodão e álcool etílico 99,5\% P.A. e lavados com água destilada para remoção de sujeira. Em seguida, foram desengraxados com acetona P.A. em banho ultrassônico por 10 min e enxaguados com água destilada e a limpeza foi finalizada com imersão dos cdps na solução desengraxante alcalina Saloclean N667, com concentração 50 g.L-1, durante $10 \mathrm{~min}$ à temperatura aproximada de $55^{\circ} \mathrm{C}$, para remoção de gorduras, óleos e para ativar a superfície. Após o desengraxe, os cdps foram lavados com água destilada, secos com jato de ar, de forma a garantir que a superfície estivesse limpa.

Os filmes de silano foram preparados partindo-se de uma mistura de silano/solução solvente, sendo o silano utilizado o viniltrietoxisilano (VS) e a solução solvente constituída de água destilada e álcool etílico (98\%) na proporção 50/50\% (v/v\%). A solução solvente teve seu pH ajustado em 4,0 com ácido acético glacial., pois a velocidade máxima de hidrólise e mínima de condensação das moléculas de silano hidrolisadas ocorrem em soluções levemente ácidas (pH em torno de 4,0). À solução solvente, sob agitação constante, adicionou-se o silano VS, formando Em seguida, sob agitação constante da solução solvente, adicionou-se $2 \%, 4 \%$ e $6 \%$ de silano VS, formando soluções 2/98, $3 / 97$ ou 4/96 (\%v/v VS/solução solvente) sendo hidrolisada à temperatura ambiente por $30 \mathrm{~min}, 45 \mathrm{~min}$ ou $60 \mathrm{~min}$. Ao final do tempo estimado para hidrólise, os cdps já limpos foram imersos na solução hidrolisada pelo processo de dip-coating durante 2 min ficando expostos por 2 min à temperatura ambiente antes de serem colocados na estufa pré-aquecida. As condições de cura do filme de silano foram fixadas em $120 \mathrm{~min}$ e $150^{\circ} \mathrm{C}$, em estufa.

Os ensaios eletroquímicos como potencial de circuito aberto (OCP), espectroscopia de impedância eletroquímica (EIE), resistência à polarização linear $(\mathrm{Rp})$ e curvas de polarização foram realizados em triplicatas, com o auxílio de um potenciostato/galvanostato da marca Metrohm Autolab, modelo PGSTAT302N com o software NOVA 1.10, conectados a um computador. Para tratamento de dados utilizou-se o Microcal ${ }^{\circledR}$ Origin ${ }^{\circledR} 8.0$.

As amostras com e sem a camada de silano foram caracterizadas eletroquimicamente numa célula convencional de três eletrodos para amostras planas, com área exposta do eletrodo de trabalho de $1 \mathrm{~cm}^{2}$. Os cdps foram utilizados como o eletrodo de trabalho. Como eletrodo de referência foi utilizado um eletrodo de $\mathrm{Ag}|\mathrm{AgCl}| \mathrm{KClsat}$ e como contra eletrodo foi empregado um fio de titânio de 1,6 mm de diâmetro e $10 \mathrm{~cm}$ de altura e revestido com ródio. O eletrólito utilizado foi uma solução aquosa de $\mathrm{NaCl}$ 0,1 mol.L-1, em temperatura ambiente, aerado e não agitado.

Os ensaios foram realizados na seguinte ordem: primeiramente foi feita a medida do potencial de circuito aberto (OCP) por 90 min, com objetivo de estabilizar o potencial de corrosão. Após a estabilização do 
OCP, as medidas de EIE foram realizadas no intervalo de frequências de $100 \mathrm{kHz}$ a $10 \mathrm{mHz}$ com 10 pontos/década e amplitude de perturbação de $10 \mathrm{mV}$ (rms). Foi considerada como resposta quantitativa dos ensaios de impedância o valor de impedância real à baixa frequência, de $31 \mathrm{mHz}$, por representar a impedância total do sistema, em meio de $\mathrm{NaCl} \mathrm{0,1} \mathrm{mol.L-1.} \mathrm{Em} \mathrm{seguida,} \mathrm{realizou-se} \mathrm{o} \mathrm{ensaio} \mathrm{de} \mathrm{resistência} \mathrm{à} \mathrm{polarização}$ linear (Rp), aplicando um potencial de perturbação de $\pm 20 \mathrm{mV}$ vs OCP, com velocidade de varredura de 0,166 mV.s-1. As curvas de Tafel foram obtidas após o ensaio de Rp sendo medidas da região catódica para a anódica no intervalo de $\pm 250 \mathrm{mV}$ vs OCP, com velocidade de varredura igual a $0,5 \mathrm{mV}$.s- 1 .

As análises por espectroscopia na região do infravermelho das amostras com revestimento do filme de silano foram realizadas utilizando um espectrofotômetro Thermo Scientific Nicolet, modelo is10, na faixa de número de onda de 4000 a $400 \mathrm{~cm}-1$, com resolução de $4 \mathrm{~cm}-1$, e diluído em pastilhas de $\mathrm{KBr}$.

As amostras com e sem revestimento do filme de silano, após 24 horas imersas numa solução de $\mathrm{NaCl} 0,1$ mol.L-1 foram analisadas por MEV. As imagens de topo e da secção transversal (amostras embutidas em resina e polidas até pasta de diamante de $1 \mu \mathrm{m}$ ) da superfície do aço galvanizado foram analisadas por MEV para avaliar as fases intermetálicas bem como a espessura da camada de Zn. A espessura da camada de zinco foi determinada em três regiões diferentes da amotra, onde foram realizadas duas medições em cada local, resultando em um total de seis medidas de espessura na amostra analisada. As imagens de MEV foram obtidas em um equipamento modelo Quanta 250F, da FEI Company, acoplado a um espectrômetro dispersivo em energia de raios X (EDS), utilizando a voltagem de feixe de $20 \mathrm{kV}$.

\section{RESULTADOS E DISCUSSÃO}

\subsection{Caracterização morfológica e microestrutural do aço galvanizado}

A caracterização morfológica e microestrutural das amostras foram obtidas por microscopia eletrônica de varredura (MEV), seguida de espectroscopia dispersiva em energia (EDS). A Figura 1 mostra as imagens de MEV com vista de topo da superfície (Figura 1a) e de secção transversal do aço galvanizado (Figuras 1b e 1c).

Na Figura 1a está apresentada a imagem da superfície de uma amostra de aço galvanizado a quente, como recebida. Como observado pela morfologia apresentada, durante o processo de solidificação há a formação de grãos e são formadas trincas intergranulares de deformação [4, 25].
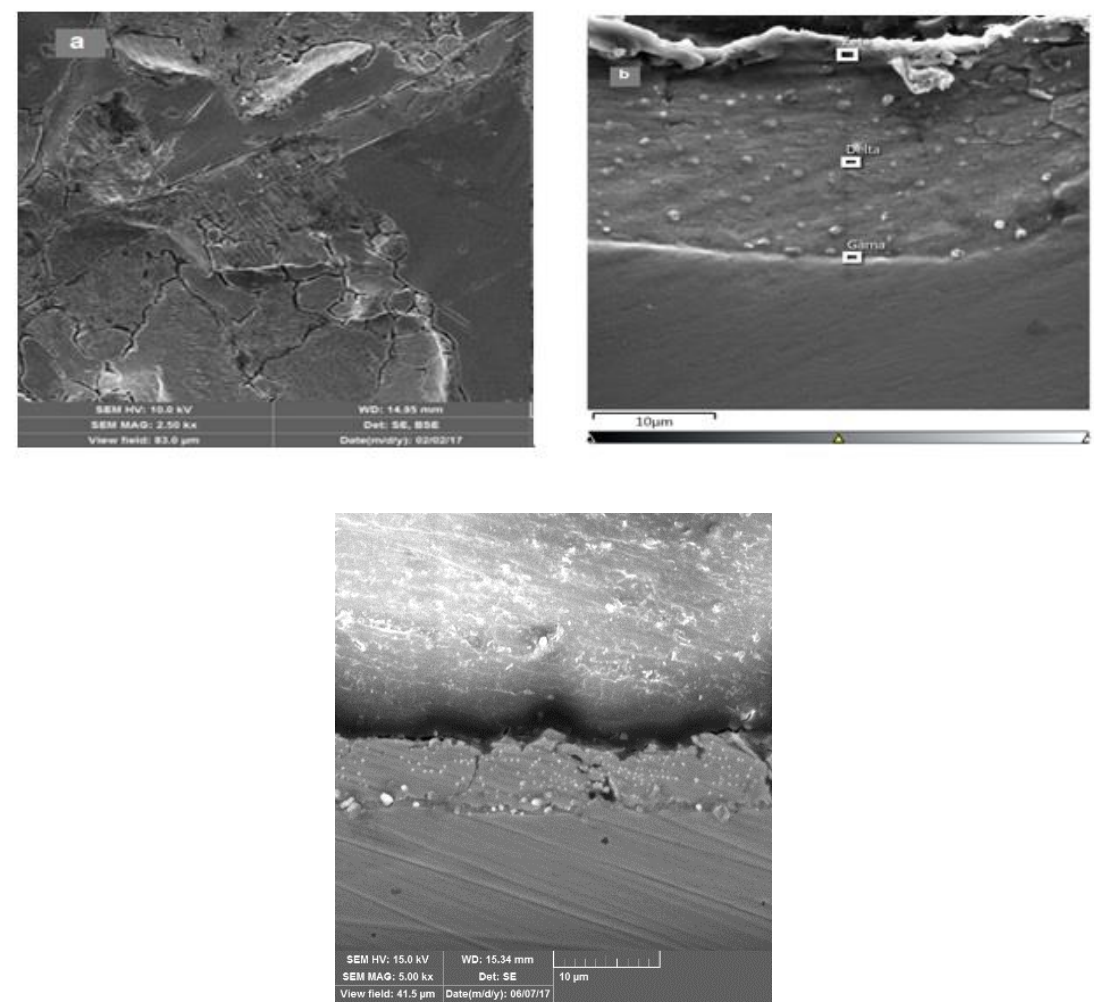

Figura 1: Imagens de MEV da superfície do aço galvanizado: (a) vista de topo e (b) e (c) seção transversal. 
Três fases intermetálicas distintas foram encontradas (Figura $1 \mathrm{~b})$ : a fase zeta $\left(\mathrm{FeZn}_{13}\right)$ mais externa e rica em zinco, a fase delta $\left(\mathrm{FeZn}_{10}\right)$ mais espessa e a fase gama $\left(\mathrm{Fe}_{5} \mathrm{Zn}_{21}-\mathrm{Fe}_{3} \mathrm{Zn}_{10}\right)$ constituída por uma fina camada entre a camada de revestimento de zinco e o aço carbono [4, 25]. Como o zinco fundido não foi supersaturado com ferro e não houve nucleação suficiente de novos cristais, não houve a formação da fase eta (१) [25]. Pode ser observada a heterogeneidade do recobrimento quanto à espessura da camada de zinco no que diz respeito à distribuição de fases intermetálicas Fe-Zn. A espessura da camada galvanizada é de aproximadamente $(10,39 \pm 1,42) \mu \mathrm{m}$, conforme especificações da USIMINAS [26] para placas do aço galvanizado por imersão à quente (Figura 1c).

A Figura 2 mostra as imagens de EDS obtidas da imagem de MEV da seção transversal (Figura 1b) relativo às três fases intermetálicas zeta (Figura 2a), delta (Figura 2b) e gama (Figura 2c) presentes na superfície do aço galvanizado. Observa-se que, embora o decréscimo no teor de Zn da superfície para o substrato seja relatado por PARANHOS et. al (2011) e MARDER (2000), os picos de Zn nos diagramas de EDS não apresentam esta tendência (Figura 2). Isto pode ser justificado pelo tempo e a temperatura do tratamento térmico e a cinética de deposição dos elementos [27, 28, 29].

Ao observar a (Figura 2c), nota-se que a fase gama apresenta teor elevado de Fe, com uma presença maior de picos de Fe no EDS, indicando ser esta a fase metálica do aço. Um percentual de alumínio é verificado em sua camada de zinco, sendo este adicionado durante o processo de galvanização com a finalidade de melhorar a qualidade dos aços galvanizados [29, 30, 31, 32].
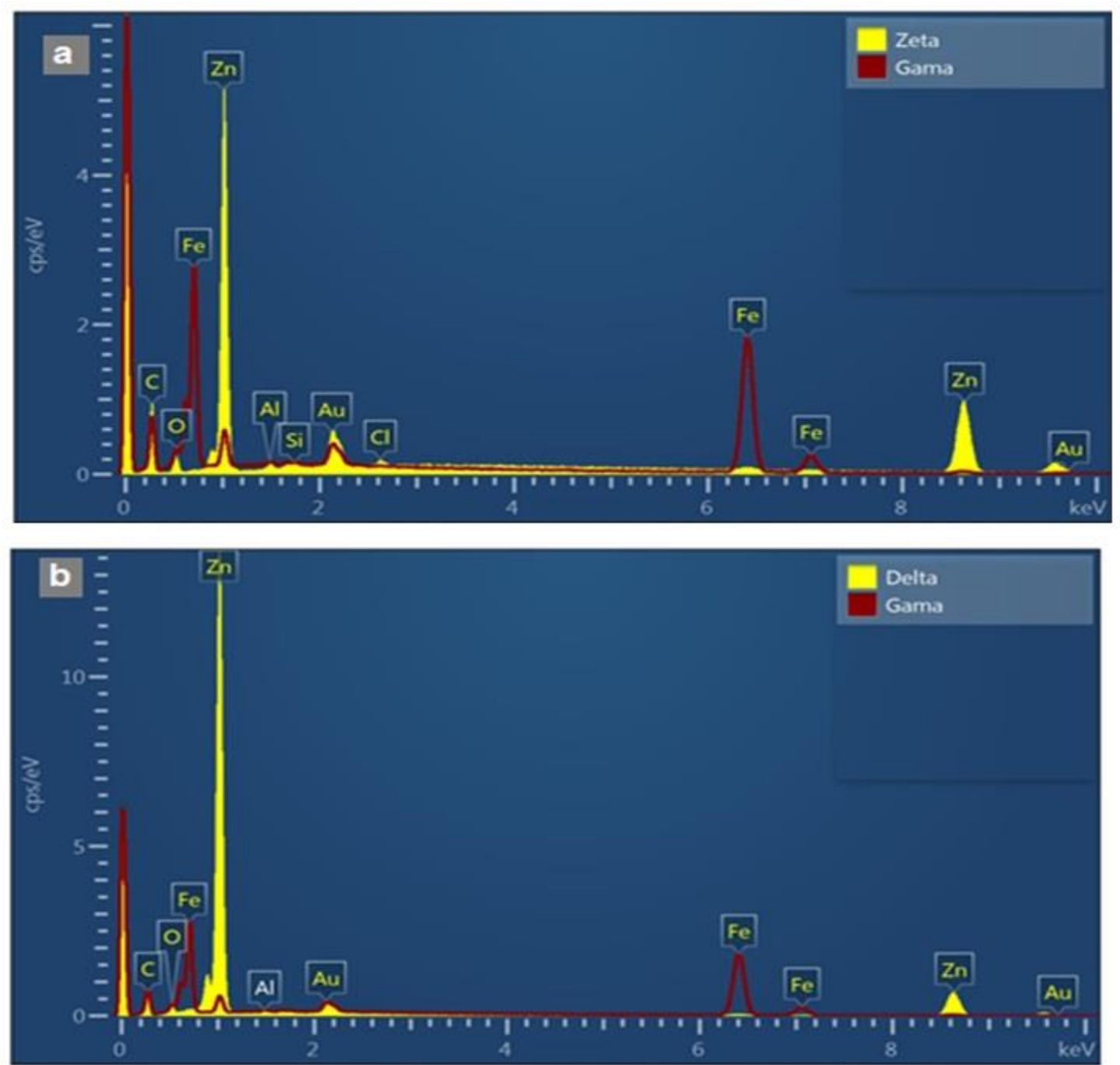


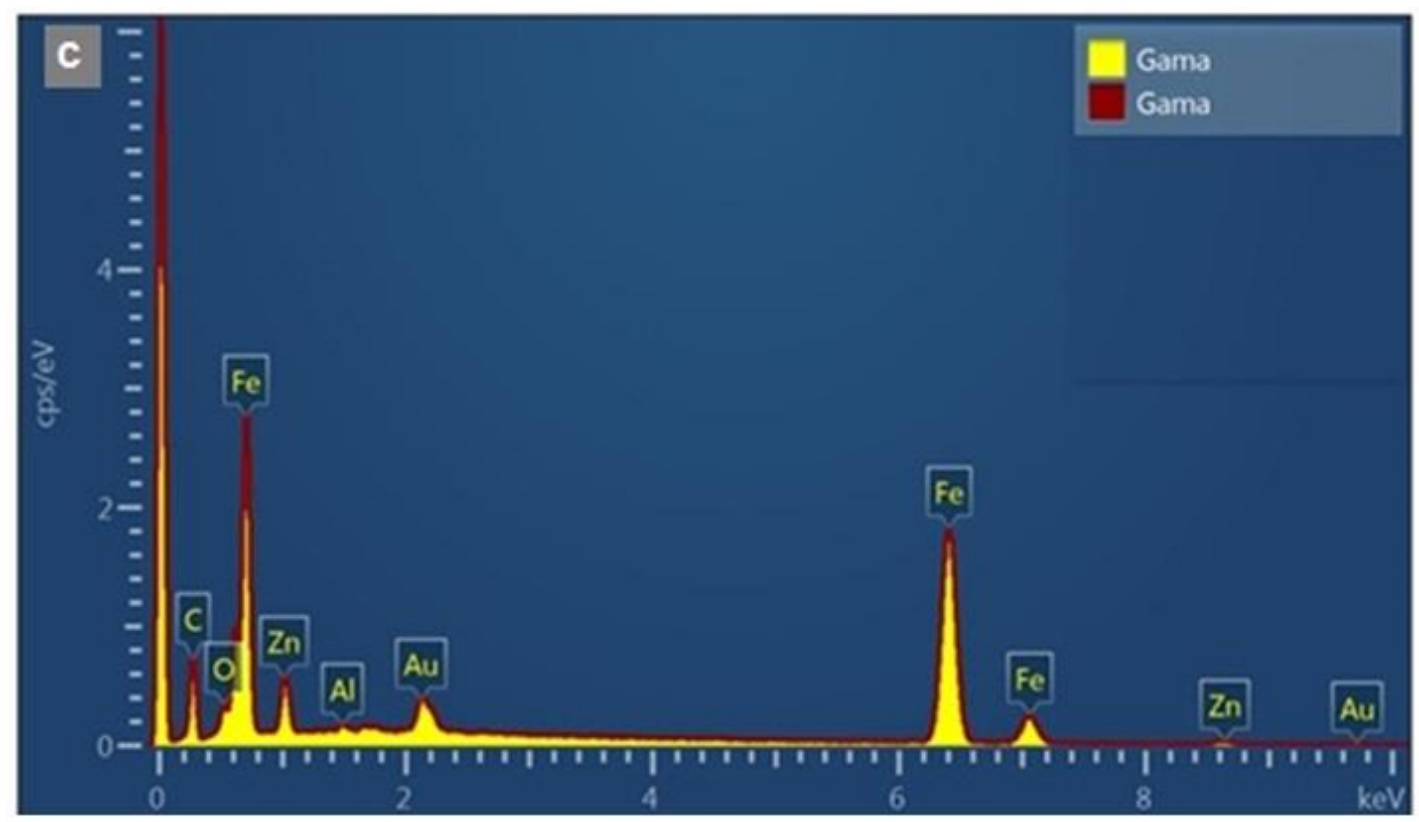

Figura 2: Espectros de EDS das fases intermetálicas do aço galvanizado: gama (a), delta (b) e zeta (c).

\subsection{Técnicas eletroquímicas}

\subsubsection{Espectroscopia de impedância eletroquímica (EIE)}

Após 90 min de estabilização do OCP, as medidas de EIE foram obtidas em triplicata. Os diagramas de EIE para as condições estudadas são apresentadas nas Figuras 3, 4 e 5. Os diagramas de EIE para as condições estudadas foram obtidos após estabilização do OCP, e são apresentados nas Figuras 3, 4 e 5. As respostas de impedância real $\left(Z^{\prime} / \mathrm{k} \Omega \cdot \mathrm{cm}^{2}\right)$ foram obtidas na faixa de frequência de $31 \mathrm{mHz}$ (baixa frequência), pois podese considerar que o valor obtido está muito próximo ao da impedância total do sistema eletroquímico em estudo.

A Figura 3 mostra os resultados de EIE fixando a concentração em 2\% de VS, mas variando o tempo de hidrólise. Pelos diagramas de Nyquist (Figura 3A) é possível observar que o valor da impedância total (Z') a $31 \mathrm{mHz}$ para todas as amostras revestidas com o filme de silano apresentam maiores valores, se comparado com a amostra não revestida. No entanto, o maior valor de Z' é observado para a condição de 30 min de hidrólise. O formato dos diagramas de Nyquist para as amostras revestidas se difere da amostra sem revestimento da amostra de aço galvanizado sem filme de silano (aço galvanizado), pois na amostra sem revestimento de silano é observada a formação de dois arcos capacitivos, enquanto que nas amostras revestidas com silano é observado apenas um. Pela análise dos diagramas -ângulo de fase $\mathrm{x} \log \mathrm{f}$ - fica claro que a amostra de aço galvanizado possui duas constantes de tempo bem definidas, sendo uma na região de altas frequências devido a interação eletrólito/camada de Zn e uma outra na região debaixas de baixas frequências, resultante da interface $\mathrm{Zn} / \mathrm{Fe}[33,34,35]$.

A presença de uma única constante de tempo para as amostras revestidas com silano, que apresenta maiores valores de ângulo de fase e uma maior faixa de frequências, revela que o filme de silano está bloqueando as reações eletroquímicas que ocorrem sobre o aço galvanizado, pois os valores de impedância e as frequências características observadas para a amostra sem revestimento de silano não são mais observados, mostrando que o filme de VS nessas condições de processamento fornece uma proteção anticorrosiva ao substrato metálico. No diagrama de Bode do módulo de impedância (|Z|) (Figura 3B) observa-se que, embora o valor de $|\mathrm{Z}|$ para as amostras tratadas com silano sejam muito próximos, estes são superiores ao valor de $|\mathrm{Z}|$ do aço galvanizado, confirmando a proteção anticorrosiva proporcionada pelo filme aplicado.

Os valores de ângulo de fase para as amostras revestidas com filme de silano são maiores do que para a amostra de aço galvanizado, revelando a formação de uma camada barreira que retarda as reações de oxidação e redução na interface eletrólito/substrato, aumentando a resistência à corrosão do aço galvanizado revestido com filme de silano. No diagrama de Bode do módulo de impedância (|Z|) (Figura 3B) observa-se que o valor do módulo de $\mathrm{Z}$ para as amostras revestidas com silano são superiores em todas as condições 
estudadas se comparado ao valor de módulo de $\mathrm{Z}$ do aço galvanizado, confirmando a proteção anticorrosiva proporcionada pelo filme aplicado. Além disso, no diagrama -ângulo de fase x log f é possível observar que o valor de ângulo de fase para as amostras tratadas com silano é maior em todas as condições e abrange uma maior faixa de frequências, quando comparado ao aço galvanizado.
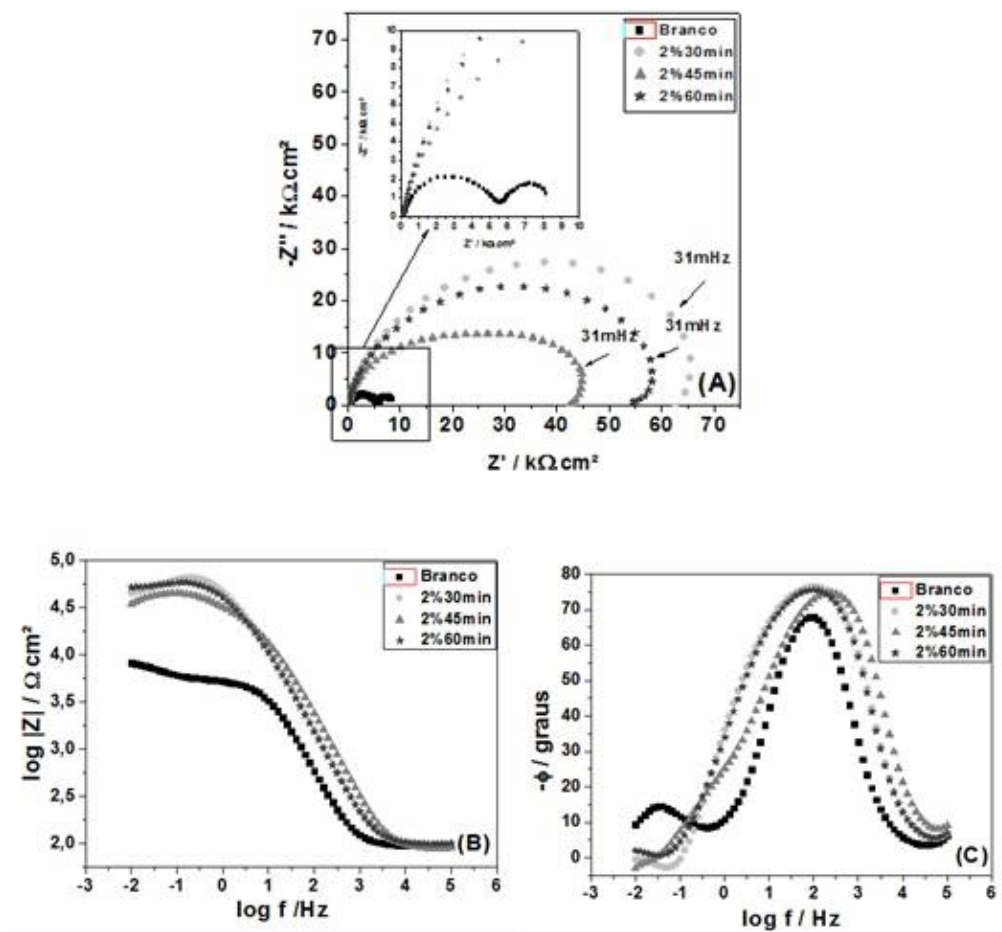

Figura 3: Diagramas de Nyquist (A), Bode módulo de Z (B) e Bode ângulo de fase (C) do aço galvanizado pré-tratado com $2 \%$ de VS em diferentes tempos de hidrólise, obtidos após 90 min de imersão em solução de $\mathrm{NaCl}$ 0,1 mol.L $\mathrm{L}^{-1}$.

Os diagramas de EIE para as amostras de aço galvanizado tratadas com $3 \%$ de VS em diferentes tempos de hidrólise são apresentados na Figura 4. O maior valor de Z' foi observado para 30 min de hidrólise (Figura 4A), que foi um comportamento similar ao das amostras utilizando concentração de $2 \%$. Isso indica que o tempo de 30 minutos é suficiente para que todos grupos silanóis sejam formados nas moléculas de VS presentes na solução e o aumento do tempo de hidrólise pode levar a uma maior probabilidade de condensação desses grupos silanóis, diminuindo a eficiência do filme formado. No diagrama de ângulo de fase $x \log$ f (Figura 4C) nota-se uma deformação de média para baixas frequências, que também é observada no diagrama de $\log |\mathrm{Z}| \mathrm{x} \log \mathrm{f}$ (Figura 4B), devido às reações interfaciais galvanizado/substrato. A constante de tempo relativa ao filme de VS está deslocada para altas frequências indicando à resistência a resistência às reações interfaciais filme/eletrólito [35, 36, 37, 38]. 

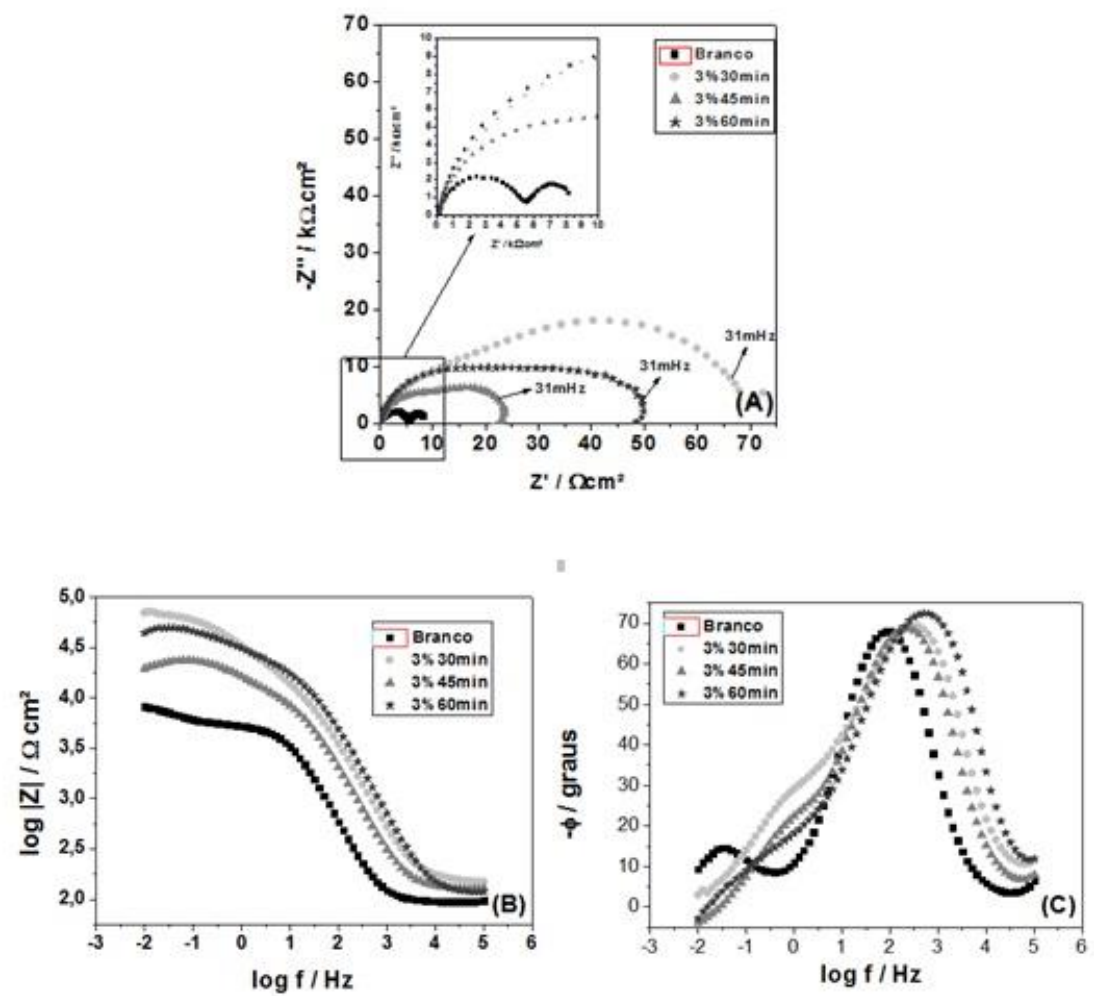

Figura 4: Diagramas de Nyquist (A), Bode módulo de Z (B) e Bode ângulo de fase (C) do aço galvanizado pré-tratado com 3\% de VS em diferentes tempos de hidrólise, obtidos após 90 min de imersão em solução de $\mathrm{NaCl} 0,1 \mathrm{~mol}^{-1} \mathrm{~L}^{-1}$.

Na condição do aço galvanizado tratado com a condição de preparo contendo 4\% de VS, o maior valor da impedância total foi obtido para a condição utilizando 60 min de hidrólise (Figura 5A). O aumento da concentração de silano para 4\%, na solução de partida, exigiu um maior tempo de hidrólise em relação às outras concentrações estudadas $(2 \%$ e $3 \%)$. . Analisando os diagramas de impedância para esta condição, nota-se que com o aumento do tempo de hidrólise há um aumento no desempenho anticorrosivo do filme estudado. Esse comportamento revela que, utilizando a concentração de $4 \%$, ao contrário das outras duas concentrações estudadas, é necessário um tempo de hidrólise superior aos 30 minutos para que todos os grupos silanóis sejam formados no silano de partida. Consequentemente, essa maior quantidade de grupos silanóis favorece durante o processo de dip-coating a adsorção de uma película heterogênea e espessa sobre o substrato metálico, resultando em um filme com propriedades anticorrosivas superiores aos observados pelas menores concentrações. O melhor desempenho do filme formado utilizando $4 \%$ de VS pode ser confirmado analisando a impedância total de todas as amostras estudadas, pois há um aumento de uma ordem de grandeza para essa melhor condição.

No diagrama de Bode módulo de $\mathrm{Z}$ (Figura 5B), observa-se que todas as amostras tratadas com filme de VS apresentam um valor de $|\mathrm{Z}|$ superior ao valor do aço galvanizado sem tratamento, com destaque para a condição do aço galvanizado tratado com $4 \%$ de VS e 60 min de hidrólise, indicando que o tratamento com silano aumenta a resistência à corrosão. Observa-se que, para 60 min de hidrólise, o ângulo de fase (Figura 5C) mantem-se por uma larga faixa de frequência indicando um melhor efeito barreira na interface filme/galvanizado revelando uma melhor propriedade de resistência à corrosão para essa condição se comparada às demais (Figuras 3C e 4C). 

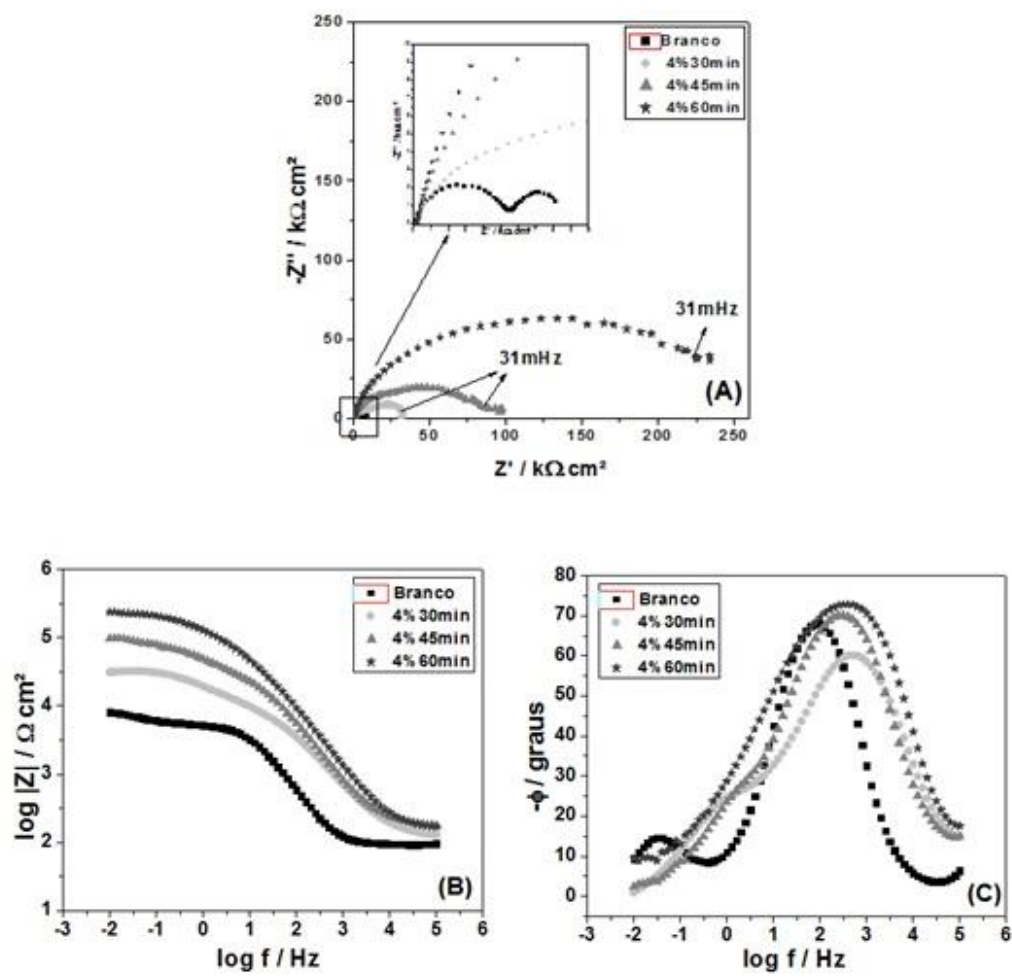

Figura 5: Diagramas de Nyquist (A), Bode módulo de Z (B) e Bode ângulo de fase (C) do aço galvanizado pré-tratado com $4 \%$ de VS em diferentes tempos de hidrólise, obtidos após 90 min de imersão em solução de $\mathrm{NaCl}$ 0,1 mol.L $\mathrm{L}^{-1}$.

A Tabela 1 apresenta os valores de impedância real (Z') e da resistência à polarização linear (Rp) para as condições estudadas. O valor de Z' para o aço galvanizado foi obtido para efeito comparativo. Nota-se que todos os valores de Z' (Tabela 1) das amostras com filme de VS são superiores ao valor de Z' do aço galvanizado indicando que o filme de silano melhora as propriedades de proteção à corrosão do aço galvanizado. No entanto, o maior valor obtido de Z' foi para a amostra tratado com 4\% de silano VS e 60 min de hidrólise, indicando ser essa a melhor condição de obtenção do filme na proteção contra a corrosão do aço galvanizado.

Tabela 1: Valores de impedância real (Z’) na frequência de $31 \mathrm{mHz}$ e valores de Rp obtidos após 110 min de imersão em solução de $\mathrm{NaCl}$ 0,1 mol.L ${ }^{-1}$.

\begin{tabular}{|c|c|c|c|c|}
\hline & Amostras de aço galvanizado & Valor Z' / k $\Omega . \mathrm{cm}^{2}$ & ${\mathrm{k} \Omega . \mathrm{cm}^{2}}^{\text {Valor }}$ & $\mathrm{Rp}$ / kohm.cm² \\
\hline & Sem filme de silano VS & 6,90 & & 8,58 \\
\hline se & Pré-tratado com $2 \%$ VS e 30 min de hidróli- & 62,70 & & 48,20 \\
\hline se & Pré-tratado com $2 \%$ VS e 45 min de hidróli- & 42,66 & & 43,09 \\
\hline se & Pré-tratado com $2 \%$ VS e 60 min de hidróli- & 56,84 & & 51,47 \\
\hline se & Pré-tratado com 3\%VS e 30 min de hidróli- & 66,14 & & 61,08 \\
\hline se & Pré-tratado com 3\%VS e 45 min de hidróli- & 22,83 & & 21,26 \\
\hline se & Pré-tratado com 3\%VS e 60 min de hidróli- & 49,70 & & 52,70 \\
\hline se & Pré-tratado com 4\%VS e 30 min de hidróli- & 32,27 & & 29,59 \\
\hline
\end{tabular}




\subsubsection{Resistência à polarização linear}

As medidas de resistência à polarização linear das amostras com e sem o filme de silano foram obtidas após o ensaio de EIE e 110 min de imersão em solução de $\mathrm{NaCl} 0,1$ mol.L $\mathrm{L}^{-1}$ e seus respectivos valores foram apresentados na Tabela 1. Os valores de Rp para todas as condições do aço galvanizado tratado com filme de VS são superiores ao valor de Rp da amostra de aço galvanizado indicando que o filme de silano atua como uma camada barreira de proteção à penetração do eletrólito, retardando a evolução do processo corrosivo. $\mathrm{O}$ maior valor de Rp é observado para a condição de $4 \%$ de silano VS e 60 min de hidrólise estando esse resultado de acordo com os resultados de EIE.

\subsubsection{Curvas de polarização}

As curvas de Tafel (Figura 6) do aço galvanizado com e sem revestimento de silano foram obtidas após o ensaio de Rp e 120 min de imersão em solução de $\mathrm{NaCl}$ 0,1 mol.L $\mathrm{L}^{-1}$. Em todas as condições estudadas com filme de VS, os valores das densidades de corrente anódica e catódica são menores do que o valor para o aço galvanizado provocando a inibição da redução do oxigênio na superfície e a dissolução do substrato. No entanto, para a condição de $2 \%$, potenciais acima de aproximadamente $-850 \mathrm{mV}$ levam a dissolução do filme de silano formado. Os potenciais de corrosão obtidos para as amostras com filme de VS estão deslocados para valores mais nobres, quando comparados ao potencial do aço galvanizado. Esse comportamento revela que o filme formado sobre a superfície diminui a cinética do processo corrosivo devido a redução das áreas ativas do substrato metálico [22, 39].

O menor valor de corrente de corrosão (Figura 6C) é observado para a amostra tratada com o filme de silano preparado com $4 \%$ de VS e 60 min de hidrólise, corroborando com os resultados de EIE. Também é possível observar que, para essa condição, o filme de silano não foi totalmente degradado na faixa de potenciais aplicada, confirmando a sua melhor proteção anticorrosiva entre as condições empregadas nesse estudo.
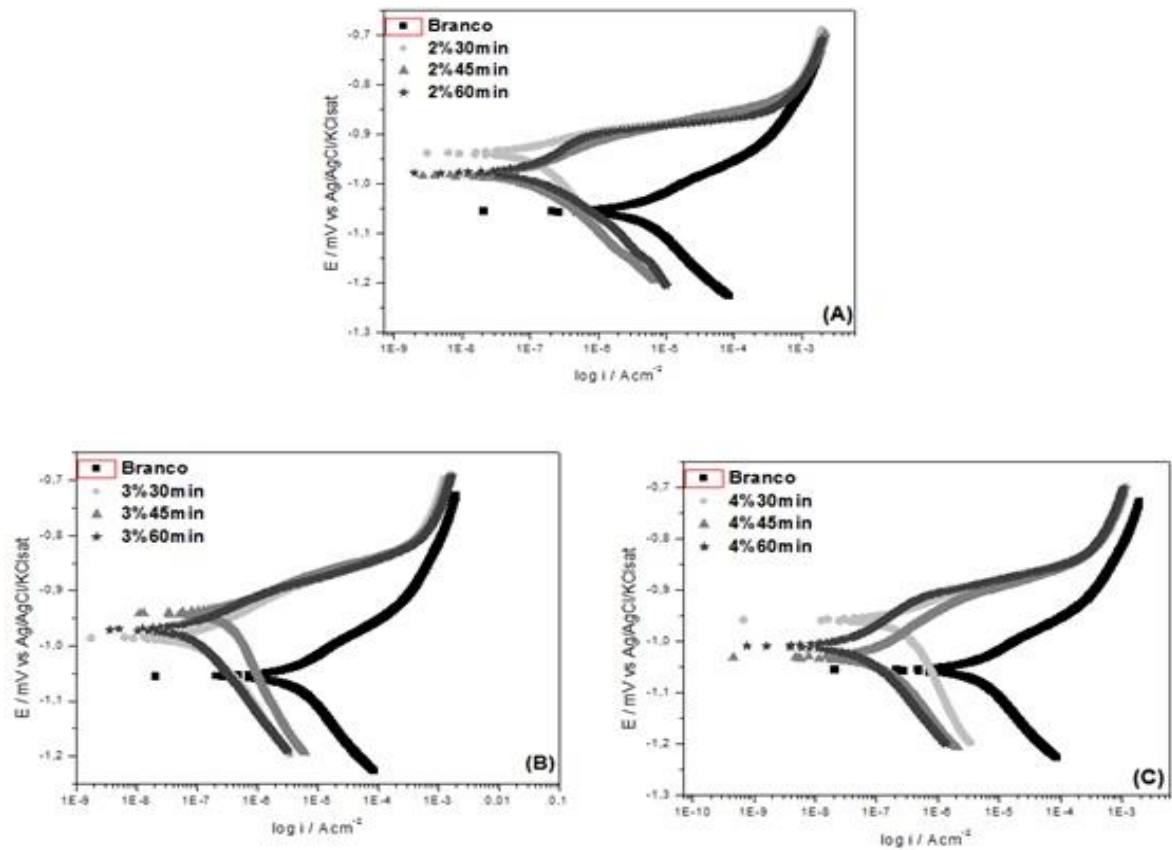

Figura 6: Curvas de Tafel do aço galvanizado com e sem pré-tratamento com (A) 2\%, (B) 3\% e (C) 4\% filme de VS, em diferentes tempos de hidrólise, obtidos após $120 \mathrm{~min}$ de imersão em solução de $\mathrm{NaCl}$ 0,1 mol. $\mathrm{L}^{-1}$. Velocidade de varredura igual a $0,5 \mathrm{mV} \cdot \mathrm{s}^{-1}$. 


\subsection{Caracterização química por espectroscopia no infravermelho espectroscopia na região do infra- vermelho (IR)}

A Tabela 2 apresenta algumas bandas de absorção para caracterizar o silano, na faixa de comprimento de onda de $700 \mathrm{~cm}^{-1}$ a $4000 \mathrm{~cm}^{-1}$ e a Figura 7 apresenta os espectros de infravermelho obtidos para as amostras de VS [40, 41, 42, 43]. Avaliando os espectros na região de infravermelho (Figura 7), nota-se que as amostras recobertas com VS apresentam algumas bandas de absorção (Tabela 2) na mesma faixa de número de onda, indicando que o filme estudado apresenta estrutura química semelhante.

Tabela 2: Bandas de absorção características do VS no espectro na região do infravermelho.

\begin{tabular}{c|c}
\hline $\begin{array}{c}\text { Número de onda da banda } \\
\left(\mathrm{cm}^{-1}\right)\end{array}$ & Atribuição da banda ao grupo \\
\hline $700-800$ & $\mathrm{C}-\mathrm{H}$ \\
$890-920$ & $\mathrm{Si}-\mathrm{O}(\mathrm{Si}-\mathrm{OH})$ \\
$1000-1250$ & Estiramento $\mathrm{Si-O}$ das ligações $\mathrm{Si}-\mathrm{O}-\mathrm{Si}$ reticuladas \\
$1300-1400$ & Dobramento de $\mathrm{CH}_{2}$ e $\mathrm{CH}_{3}$ \\
$1600-1670$ & Deformação axial de $\mathrm{C}=\mathrm{C}-\mathrm{H}$ \\
$2900-3000$ & Estiramento simétrico e assimétrico C-H $\left(\mathrm{CH}_{2}\right.$ e $\left.\mathrm{CH}_{3}\right)$ \\
$3200-3700$ & Deformação axial de O-H do grupo $\mathrm{Si}-\mathrm{OH}$ e de água \\
\hline
\end{tabular}

A Figura 7 corresponde aos espectros das camadas de VS. Em $957 \mathrm{~cm}^{-1}$ indica a presença de grupo Si$\mathrm{OH}$ devido à presença de silanóis produzidos na hidrólise do silano e a não condensação de todos eles. Em $1075 \mathrm{~cm}^{-1}$ encontra-se a banda correspondente ao estiramento $\mathrm{Si}-\mathrm{O}$ das ligações $\mathrm{Si}-\mathrm{O}-\mathrm{Si}$ que foram reticuladas durante o processo de cura. Em $1389 \mathrm{~cm}^{-1}$ encontra-se a banda característica dos dobramentos $\mathrm{CH}_{2} \mathrm{e} \mathrm{CH}_{3}$ e em $2972 \mathrm{~cm}^{-1}$ um pico de estiramento C-H. O pico em $1601 \mathrm{~cm}^{-1}$ é característico do grupo vinil $(\mathrm{C}=\mathrm{C})$, ou seja, o pico corresponde a deformação axial do $\mathrm{C}=\mathrm{C}-\mathrm{H}$.

Estudos realizados sobre a caracterização dos filmes de silano detectaram as mesmas bandas referentes aos grupos típicos de silanos que foram detectadas neste trabalho [40, 41, 42, 44].

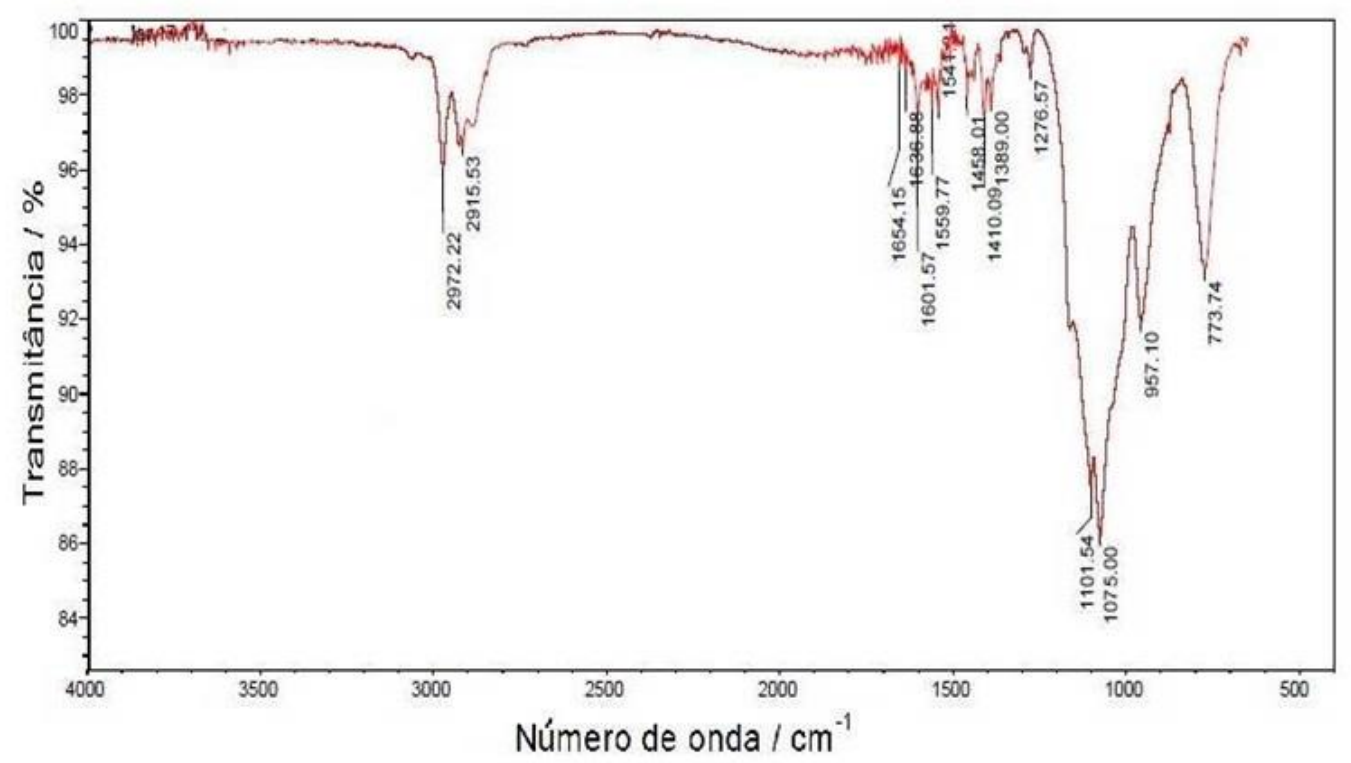

Figura 7: Espectros na região do infravermelho das amostras de aço galvanizado recobertas com o filme de silano $4 \%$ VS, com cura $150^{\circ} \mathrm{C}$ por $60 \mathrm{~min}$. 


\subsection{Caracterização morfológica por microscopia eletrônica de varredura (MEV)}

A Figura 8 apresenta as imagens de MEV e os espectros de EDS da superfície do aço galvanizado tratado com filme de silano VS (4\% de silano e 60 min de hidrólise). As imagens de MEV mostram a presença do filme de silano na superfície do galvanizado. No entanto, é possível perceber a presença do filme de silano nas regiões mais escuras (Figura $8 \mathrm{c}$ e f) revelando que a formação do filme não é homogênea ao longo da superfície (Figura 8). Isto provavelmente ocorre devido à formação de grãos nas fases intermetálicas do galvanizado (Figura 1A) que torna a superfície irregular dificultando a adsorção e reticulação do filme na superfície [4, 23, 29]. Isto se confirma com os espectros de EDS obtidos nas regiões escuras (espectros 4 e 7 Figura 8 c e f) e nas regiões claras (espectros 5 e 6- Figura 8 d e e), que revelam um pico maior de Si nos espectros 4 e 7 (regiões escuras) e um pico muito menor no espectro 6 (região clara). No entanto, a região 5 que é uma região clara, apresenta um pico de Si maior que o espectro 6 indicando ser uma falha na região do espectro 4. Esta falha se deve à má formação da fase delta, que apresenta trincas, grãos e heterogeneidades (Figura 1b) [4, 29], dificultando a adsorção e reticulação do filme. O resultado dessas análises possibilita afirmar que o filme de silano tem maior facilidade de adsorção na fase intermetálica delta (região escura) do galvanizado.
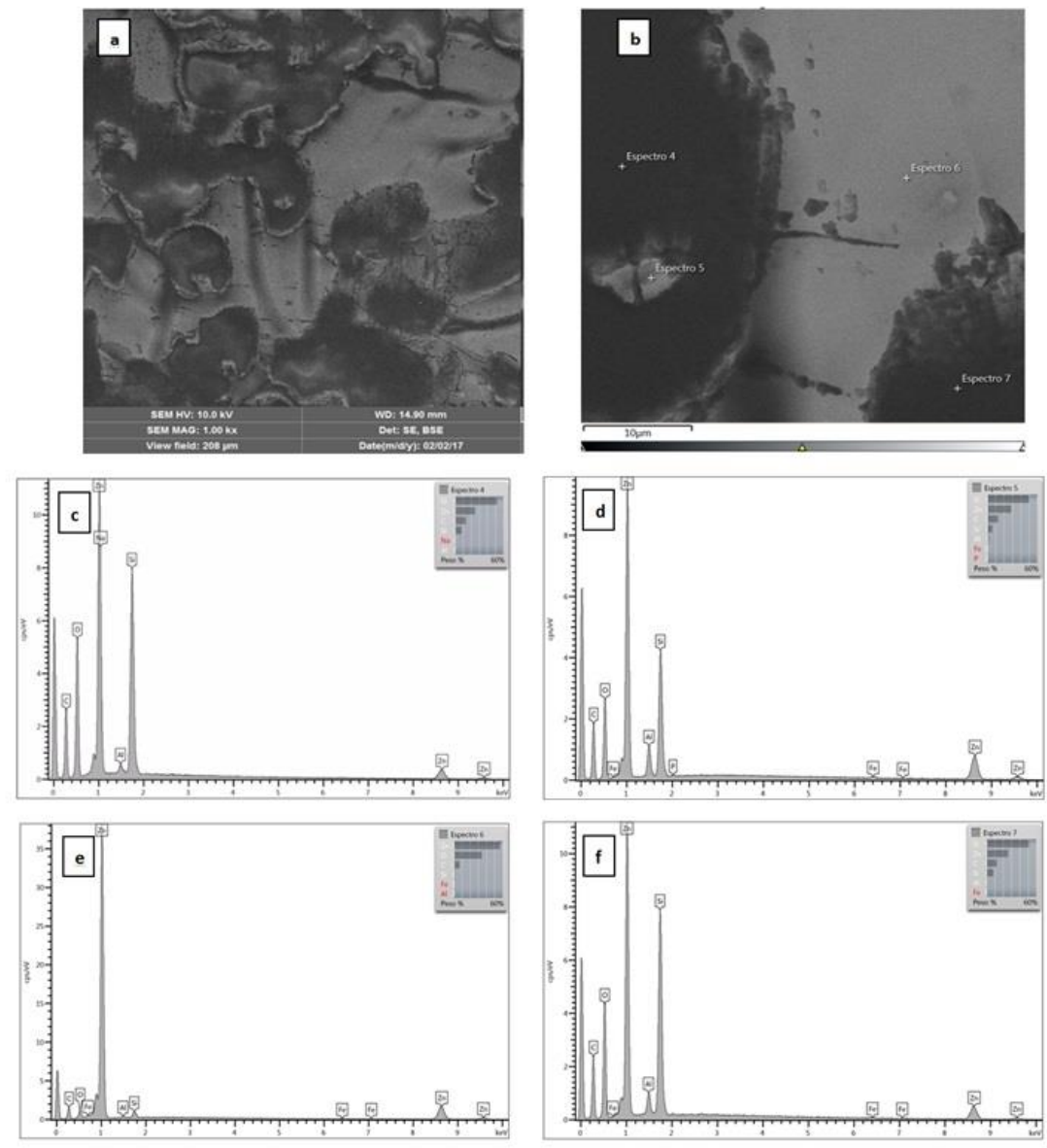

Figura 8: Imagens de MEV (a e b) e os espectros de EDS (c, d, e, f) da superfície do aço galvanizado tratado com filme de silano VS (4\% de silano e 60 min de hidrólise)

As amostras com e sem pré-tratamento com filme de silano VS (4\% e 60 min de hidrólise) foram imersas por $24 \mathrm{~h}$ em solução de $\mathrm{NaCl} 0,1$ mol.L $\mathrm{L}^{-1}$ e as imagens de $\mathrm{MEV}$ são apresentadas na Figura 9 . O aço galvanizado sem tratamento com filme de VS após ataque eletrolítico de $24 \mathrm{~h}$ apresenta produtos de corrosão de forma generalizada na superfície do galvanizado (Figura 9a), enquanto que a amostra tratada com filme de VS apresenta produtos de corrosão nas regiões claras (Figura 9b) onde a quantidade de filme é menor, representado pelo pico de Si (Figura $8 \mathrm{~d}$ e e). Na região escura, não há formação de produtos de corrosão devido à presença de um filme fino, nanométrico [43], heterogêneo, representado pelo pico de Si (Figura 8c e 
f), dificultando a penetração do eletrólito e retardando a evolução do processo corrosivo nesta região.
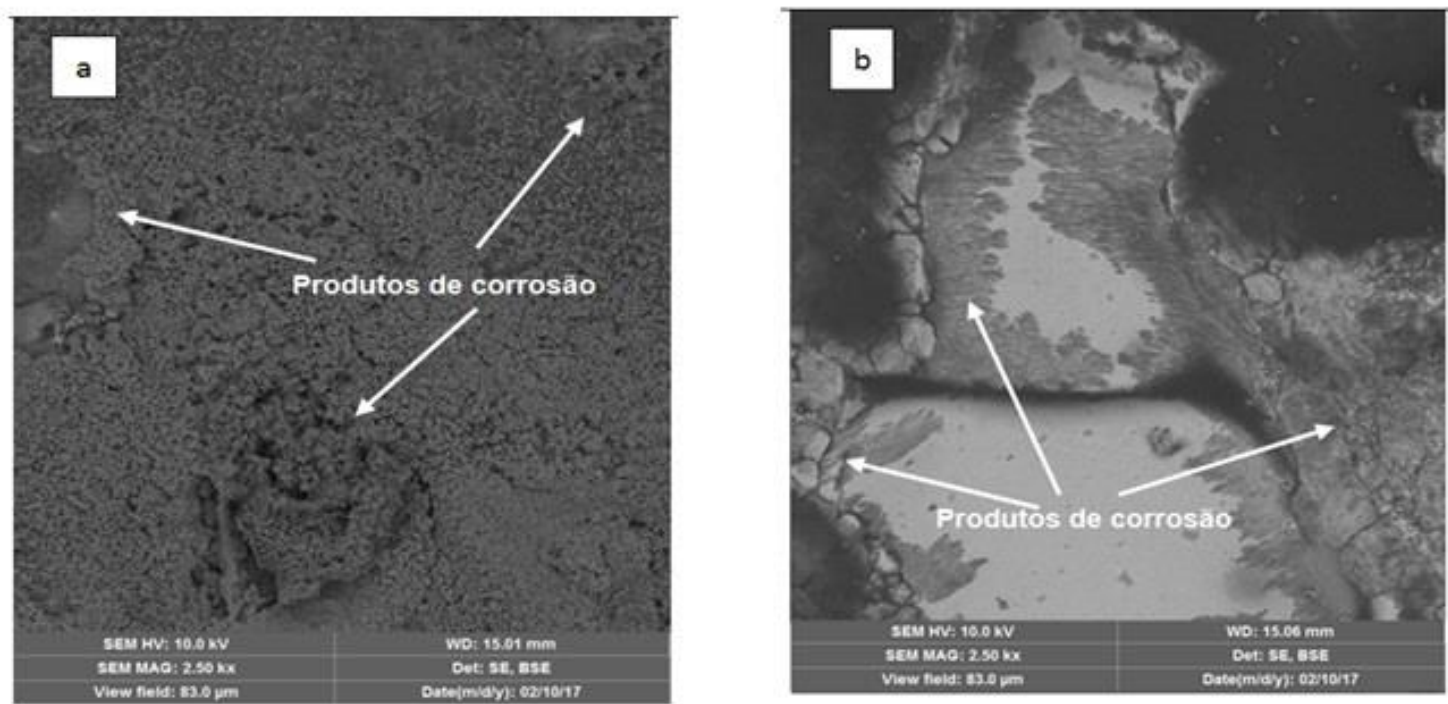

Figura 9: Imagens de MEV da (a) superfície do aço galvanizado sem tratamento e (b) da superfície do aço galvanizado tratado com filme de silano VS (4\% de silano e 60 min de hidrólise).

\section{CONCLUSÃO}

As imagens de MEV e os resultados de EDS indicam que a microestrutura do aço galvanizado tende a formar trincas e há a formação de grãos devido ao processo de solidificação. As imagens obtidas por MEV revelaram que o processo corrosivo na superfície do aço galvanizado é retardado devido ao efeito barreira da camada de silano. E mostrou que após $24 \mathrm{~h}$ de imersão em solução de $\mathrm{NaCl} 0,1 \mathrm{~mol} \cdot \mathrm{L}^{-1}$, produtos de corrosão foram identificados de forma generalizada na superfície do aço galvanizado, enquanto que a amostra com filme de VS apresenta produtos de corrosão em menores proporções.

Os resultados obtidos por espectroscopia de impedância eletroquímica (EIE) mostraram que a adição do filme de VS como tratamento sobre o aço galvanizado inibe o processo corrosivo do substrato, pois todas as condições estudadas apresentaram uma maior resistência à corrosão do que a amostra sem a presença do filme protetor de silano.

Dentro das condições de preparo do VS estudadas nesse trabalho, o tratamento que apresentou o maior desempenho anticorrosivo para o aço galvanizado em $\mathrm{NaCl}$ 0,1 mol/L, foi a condição contendo $4 \%$ de VS, hidrolisada por $60 \mathrm{~min}$. Nessa concentração, foi observado que o aumento do tempo de hidrólise proporcionou um aumento gradativo no desempenho anticorrosivo do filme e, portanto, um tempo maior de hidrólise, bem como maiores concentrações do silano VS podem futuramente ser estudados para resultados ainda melhores. No entanto, o aumento da concentração de VS pode ser economicamente desfavorável.

O tratamento com o silano VS se mostra promissor em relação à proteção contra corrosão do aço galvanizado utilizado principalmente na indústria automobilística e de linha branca além de serem ambientalmente amigáveis do que os métodos de tratamento (fosfatização e cromatização) convencionalmente utilizados.

\section{AGRADECIMENTOS}

Os autores gostariam de agradecer aos seguintes laboratórios: LAMMA (Laboratório de Materiais e Meio Ambiente da Universidade Estadual de Santa Cruz) e a USIMINAS pelo fornecimento do aço galvanizado. Os autores também agradecem à FAPESB pelo financiamento do projeto (PET0015/2016).

\section{BIBLIOGRAFIA}

[1] GENTIL,V. Corrosão. 5 ed. Rio de Janeiro, LTC - Livros Técnicos e Científicos. Editora S.A., 2007. 
[2] CALLISTER JUNIOR, W. D., RETHWISCH, D. G. Ciência e engenharia de materiais: uma introdução. $8^{\mathrm{a}}$ Ed., LTC, 2012.

[3] CHIAVERINI, V. Aços e ferros fundidos: características gerais, tratamentos térmicos, principais tipos. $7^{a}$ ed., Associação Brasileira de Metalurgia e Materiais, São Paulo, 2008.

[4] PARANHOS, R. M. V., LINS, V. F. C., ALVARENGA, E. A., et al., "Optimisation of electrochemical stripping of galvannealed interstitial free steels", Surface Engineering, v. 27, pp. 676-682, 2011.

[5] PLOYPECH, S., JEARANAISILAWONG, P., BOONYONGMANEERAT, Y. "Influence of thickness of intermetallic layers on fracture resistance of galvanized coatings", Surface and Coatings Technology, v. 223, pp. 1-5, 2013.

[6] ZAND, R. Z., VERBEKEN, K., FLEXER, V., et al., "Effects of ceria nanoparticle concentrations on the morphology and corrosion resistance of ceriumesilane hybrid coatings on electrogalvanized steel substrates", Materials Chemistry and Physics, v. 145, pp. 450-460, 2014.

[7] BOSSARDI, K. "Nanotecnologia aplicada a tratamentos superficiais para o aço carbono 1020 como alternativa ao fosfato de zinco", Dissertação de M.Sc., Engenharia de Minas, Metalúrgica e de Materiais, Universidade Federal do Rio Grande do Sul, RS, 2007.

[8] OLIVEIRA, M. F., GRASSI, M., GALLINA, A. L., et al., "Development and Characterization of an Alternative Process: Nanoceramic Application to the Treatment of Carbon Steel", Materials Science Forum, Trans Tech Publications, pp. 143-148, 2015.

[9] BALAN, P., SHELTON, M. J., CHING, D. O. L., et al., "Modified silane films for corrosion protection of mild steel", Procedia Materials Science, v. 6, pp. 244-248, 2014.

[10] MARCOLIN, P., PEDERIVA, L., SALVADOR, D. G., et al., "Influência de três pré-tratamento de superfície com posterior aplicação de tinta poliéster na resistência a corrosão do aço AISI 1008", Tecnologia em Metalurgia, Materiais e Mineração, v. 14, n. 4, 2017.

[11] MITTAL, K.L. Silanes and Other Coupling Agents. v. 4, VSP, Brill/Leiden, 2007.

[12] ZHU, D., OOIJ, W. J. V., "Enhanced corrosion resistance of AA 2024-T3 and hot-dip galvanized steel using a mixture of bis- triethoxysilylpropyl]tetrasulfide and bis- trimethoxysilylpropyl]amine", Electrochimica Acta, v. 49, n.7, pp. 1113-1125, 2004.

[13] FEDEL, M., DRUART, M. E., OLIVIER, M., et al., "Compatibility between cataphoretic electrocoating and silane surface layer for the corrosion protection of galvanized steel", Progress in Organic Coatings, v. 69, n. 2, pp. 118-125, 2010.

[14] PERES, R. N., CARDOSO, E. S. F., MONTEMOR, M. F., et al., "Influence of the addition of $\mathrm{SiO} 2$ nanoparticles to a hybrid coating applied on an AZ31 alloy for early corrosion protection", Surface and Coatings Technology, v. 303, pp. 372-384, 2016.

[15] PLUEDDEMANN, E. P. Silane Coupling Agents, 2nd Ed., Plenum Press, New York, 1991.

[16] WANG, L., LIU, C.-S., YU, H.-Y., et al., "Structure and Corrosion Resistance of a Composite $\gamma$-Amino Propyl Triethoxy Silane and $\gamma$-Glycidoxy Propyl Trimethoxy Silane Conversion Coating on Galvanized Steel", Journal of Iron and Steel Research, v. 19, n.11, pp. 46-51, 2012.

[17] ASADI, N., NADERI, R., SAREMI, M., et al., "Study of the Effect of Sol pH and Nanoclay Incorporation on the Corrosion Protection Performance of a Silane Sol-Gel Coating", Journal of Ultrafine Grained and Nanostructured Materials, v. 47, n. 1, p. 9-14, 2014.

[18] BERA, S., ROUT, T. K., UDAYABHANU, G., et al., "Water-based \& eco-friendly epoxy-silane hybrid coating for enhanced corrosion protection \& adhesion on galvanized steel", Progress in Organic Coatings, v. 101, pp. 24-44, 2016.

[19] DALMORO, V., SANTOS, J. H. Z., ALEMÁN, C., et al., "An assessment of the corrosion protection of AA2024-T3 treated with vinyltrimethoxysilane/(3-glycidyloxypropyl) trimethoxysilane", Corrosion Science, v. 92 , pp. 200-208, 2015.

[20] ANSARI, F., NADERI, R., DEHGHANIAN, C. "Study on the protective function of cloisite incorporated silane sol-gel coatings cured at different conditions", Applied Clay Science, v. 114, pp. 93-102, 2015.

[21] FEDEL, M., POELMAN, M., ZAGO, M., et al., "Influence of formulation and application parameters on the performances of a sol-gel/clay nanocomposite on the corrosion resistance of hot-dip galvanized steel", Part II. Effect of curing temperature and time. Surface \& Coatings Technology, v. 274, pp. 9-17, 2015.

[22] DAUDT, N. F., MENEZES, T. L., FERREIRA, J. Z. "O efeito da adição de inibidores de corrosão em 
filmes a base de monosilanos na ação protetora ao aço carbono", Revista Eletrônica de Materiais $e$ Processos, v.8, n.1, pp. $12-19,2013$.

[23] YING-SING, L., WRIGHT P. B., PURITT, R., et al., "Vibrational spectroscopic studies of vinyltriethoxysilane sol-gel and its coating”, Spectrochimica Acta Part A, v. 60, pp. 2759-2766, 2004.

[24] SIGMA ALDRICH - Product Information - Organofunctional Silanes - 175560 - Triethoxyvinylsilane. Disponível em: http://www.sigmaaldrich.com. Acessado em 07 de agosto de 2019.

[25] MARDER, A. R. “The metallurgy of zinc-coated steel”, Progress in Materials Science. v. 45, pp. 191271,2000 .

[26] USIMINAS - Nossos produtos - Galvanizados por imersão a quente. Disponível em: http://www.usiminas.com. Acessado em 09 de setembro de 2019.

[27] HAMID, Z. A., REHIM, S. S. A. E., SHAMA, A. A., et al., "Improvement the Corrosion Resistance for the Galvanized Steel by Adding Sn”, Journal of Surface Engineered Materials and Advanced Technology, v. 6, pp. 58-71, 2016.

[28] PORTER, F. C. Corrosion Resistance of Zinc and Zinc Alloys. CRC Press, New York, 1994.

[29] WIENSTROER, S., FRANSEN, M., MITTELSTÄDT, H., et al., "Zinc/Iron Phase Transformation Studies on "galvannealed" Steel Coatings by X-Ray Diffraction", JCPDS International Centre for Diffraction, v. 46, 2003.

[30] CABRAL, E. R. Galvanização: sua aplicação em equipamento elétrico. CEPEL - Centro de Pesquisas de Energia Elétrica, 1979.

[31] PERSSON, D., THIERRY, D., KARLSSON, O. "Corrosion and corrosion products of hot dipped galvanized steel during long term atmospheric exposure at different sites world-wide”, Corrosion Science, v. 126, pp. 152-165, 2017.

[32] SHIBLI, S. M. A., MEENA, B. N., REMYA, R. "A review on recent approaches in the field of hot dip zinc galvanizing process”, Surface and Coatings Technology, v. 262, pp. 210-215, 2015.

[33] AOKI, I. V., MELO, H. G. "Fundamentos da técnica de Espectroscopia de Impedância Eletroquímica (EIE)", Metalurgia \& Materiais, v. 66, pp. 201-206, 2009.

[34] MORETO, J. A., "Estudo da corrosão e corrosão-fadiga em ligas de Al e Al -Li de Alta Resistência para aplicação Aeronáutica", Tese de D.Sc., Ciências e Engenharia de Materiais, Escola de Engenharia de São Carlos, Universidade de São Paulo, São Carlos, 2012.

[35] PALOMINO, L.E. M. "Comparative Investigation of the Adhesion of Ce Conversion Layers and Silane Layers to a AA 2024-T3 Substrate Through Mechanical and Electrochemical Tests", Materials Research, v. 10, n. 4, pp. 399-406, 2007.

[36] ARAMAKI, K., "Self-healing mechanism of an organosiloxane polymer film containing sodium silicate and cerium(III) nitrate for corrosion of scratched zinc surface in $0.5 \mathrm{M} \mathrm{NaCl}$ ”, Corrosion Science, v. 44, p. 1621-1632, 2002.

[37] CAPELOSSI, V. R., AOKI, I. V., "Influence of sonication on anticorrosion properties of a sulfursilane film dopped with Ce (IV) on galvannealed steel”, Progress in Organic Coatings, v. 76, pp. 791-801, 2013.

[38] FEDEL, M., OLIVIER, M., POELMAN, M., et al., "Corrosion protection properties of silane pretreated powder coated galvanized steel”, Progress in Organic Coatings, v. 66, pp. 118-128, 2009.

[39] SUEGAMA, P. H., MELO, H. G., RECCO, A. A. C., et al., "Corrosion behavior of carbon steel protected with single and bi-layer of silane films filled with silica nanoparticles", Surface \& Coatings Technology, v. 202, pp. 2850-2858, 2008.

[40] VAN OOIJ, W.J., ZHU, D., STACY, M., et al., "Corrosion protection properties of organofunctional silanes - An overview”, Tsinghua Science and Technology, v. 10, n. 6, pp. 639-665, 2005.

[41] AQUINO, I. P., "Caracterização da superfície do aço-carbono ABNT 1008 revestida com organo-silanos por meio de técnicas eletroquímicas e físico-químicas", Dissertação de M.Sc., Escola Politécnica da Universidade de São Paulo, 2006.

[42] MONTEMOR, M. F., ROSQVIST, A., FAGERHOLM, H., et al., The early corrosion behavior of hot dip galvanized steel pre- treated with bis-1,2-(triethoxysilyl)ethane, Progress in Organic Coatings, v. 51, pp. 188-194, 2004.

[43] CAPELOSSI V. R., "Filmes à base de polissilanos com pré-tratamentos protetores contra corrosão de aço “galvannealed”, Tese de M.Sc., Escola Politécnica da Universidade de São Paulo, São Paulo, 2011. 
[44] SILVERSTEIN, R. M., WEBSTER, F. X., KIEMLE, D. J. Identificação Espectrométrica de Compostos Orgânicos, 7 ed., Rio de Janeiro, Editora LTC, Livros Técnicos e Científico, 2010.

\section{ORCID}

Tarcilla Silva dos Santos

https://orcid.org/0000-0002-2249-3999

Fernando Cotting

http://orcid.org/0000-0001-5980-0078

Vera Rosa Capelossi

http://orcid.org/0000-0002-0212-8388 